\title{
Mode of Delivery of Women with Complicated Pregnancy in a Tertiary Level Hospital in Bangladesh
}

\author{
Khan MTR ${ }^{1}$, Alam MA², Abdullah SAHM ${ }^{3}$, Zafreen $\mathrm{F}^{4}$ \\ DOI:https://doi.org/10.3329/jafmc.v16i2.55294
}

\begin{abstract}
Introduction: Every year, a great number of women die from pregnancy or childbirth related complications, which can be prevented. In developing countries, they don't have access to maternal health services and cannot afford high quality care. Maternal death is usually occurs due to three delays: in decision making to seek care, reaching care and receiving care. Right decision at the right time regarding mode of delivery has a direct impact on healthy outcome of pregnancy as well as the maternal wellbeing.
\end{abstract}

Objectives: To find out the outcome of complicated pregnancy.

Materials and Methods: This cross-sectional observational study was conducted at obstetrics and gynaecology department of Dhaka Medical College Hospital from January to June 2011. Total 107 mothers who delivered recently with or without pregnancy complications were selected purposively. Data were collected by face to face interview with semi structured questionnaires. Verbal consents were taken prior to interview.

Results: Among the respondents about $68.2 \%$ had antenatal complications and about $31.8 \%$ had no antenatal complication. Among the women having antenatal complications, $83.6 \%$ delivered by caesarean section and only $16.4 \%$ delivered by normal vaginal delivery. There was significant association of antenatal complications with mode of delivery by caesarean section.

Conclusion: Women having antenatal complications had significant association with caesarean section. Though every pregnancy is at risk but early detection of complications, timely referral and timely intervention can save lives of many women during the process of child birth.

Key-words: Complicated pregnancy, Antenatal Care, Early detection, Timely intervention.

\section{Introduction}

Despite considerable reductions in maternal mortality over the previous decades, several countries, particularly developing, were unable to meet the target. The global maternal death has dropped 44 percent since 1990 by 2017, yet 830 women die per day from pregnancy and childbirth related complications. UNFPA estimated that 303,000 women died from pregnancy or childbirth related causes in $2015^{1}$.

There are multiple factors associated with maternal mortality that includes both medical and social causes. The most common causes are postpartum bleeding (15\%), complications from unsafe abortion (15\%), hypertensive disorders of pregnancy $(10 \%)$, postpartum infections (8\%), and obstructed labour (6\%)2. Other causes include blood clots (3\%) and pre-existing conditions $(28 \%)^{3}$. There is a distinction between a direct maternal death that is the result of a complication of the pregnancy, delivery or management of the two and an indirect maternal death ${ }^{4}$.

Bangladesh has made significant progress in reducing maternal mortality ratio which has been fallen from 434 per 100,000 live births in 2000 to 173 per 100,000 live births in $2017^{5}$, nevertheless, there are considerable disparities in accessing maternal and child health care ${ }^{6}$. Lack of access to health care facilities, low uptake of antenatal care, delayed decision making in reaching health facilities for childbirth by the pregnant women herself and her family members contribute to social factors of maternal mortality in Bangladesh ${ }^{7,8}$.

ANC has long been seen as an essential service in ensuring safe motherhood and a critical component of the continuum of care for pregnant mothers along with newborns ${ }^{9}$. The latest maternal mortality survey in Bangladesh suggests that progress in reducing maternal mortality has stopped as only $37 \%$ of pregnant women have attended at least four ANC visits ${ }^{10}$.

Maternal and child birth care encompasses several levels of services, beginning with the detection of symptoms and care provided by the non health persons at home and continuing through care delivered in a health facility. At each level, the timely service and quality of care is crucial. We know about three delay model, which has been developed to identify cause of delay in obstetric care in low recourse settings. According to three delay models, delay in seeking care, delay in reaching care and delay in receiving care are attributable to the adverse outcomes from obstetric complications from the onset to the ultimate outcome of the complicated pregnancy ${ }^{11}$. Delays in receiving adequate and appropriate care may result from an inadequate number of trained providers, lack of appropriate supplies, and the lack of urgency or

1. Lt Col Morsheda Tania Rashid Khan, MBBS, MPH, Commanding Officer, 81 Field Ambulance, Mymensingh (E-mail: taniarashid1971@gmail.com) 2. Dr Md Ashraful Alam, MBBS, MPH, PhD, National Institute of Preventive and Social Medicine, Mohakhali, Dhaka 3. Lt Col Syed Abul Hassan Md Abdullah MBBS, MPH, ADGMS (Training), Directorate General of Medical Services, Dhaka 4. Dr Farzana Zafreen, MBBS, MPH, Associate Professor and Head, Department of Community Medicine, Medical College for Women \& Hospital, Uttara, Dhaka 
understanding of an emergency ${ }^{12}$. The three delays model illustrates that there are a multitude of complex factors, both socioeconomic and cultural, that can result in maternal death ${ }^{10}$.

A lot of progress has been made since the United Nations made the reduction of maternal mortality part of the Millennium Development Goals (MDGs) in $2000^{13}$. The United Nations has more recently developed a list of goals termed the Sustainable Development Goals. The target of the third Sustainable Development Goal (SDG) is to reduce the global maternal mortality rate (MMR) to less than 70 per 100,000 live births by $2030^{14}$. The WHO has also developed a global strategy and goal to end preventable death related to maternal mortality ${ }^{8}$.

Therefore, this paper focused on the mode of childbirth of women who have experienced complication during pregnancy in a tertiary hospital setting in Bangladesh. The findings can be used to guide initiatives targeted at minimizing delays in obtaining emergency obstetric care and lowering the frequency of maternal death and morbidity in Bangladesh.

\section{Materials and Methods}

This cross-sectional observational study was conducted at the Obstetrics and Gynecology department of Dhaka Medical College Hospital from January to June 2011. Total 107 mothers who delivered recently with or without pregnancy complications and who were willing to participate were selected purposively. Data were collected by face to face interview with semi structured questionnaires. Verbal consents were taken prior to interview. Data processing and analyses were done using SPSS version 17 . The test statistics used to analyze the data were descriptive statistics and chi square ( $x 2)$. Level of significance was set at $p<0.5$. Prior to initiation of the study ethical clearance was taken from appropriate Ethical Committee of NIPSOM

Table-I: Distribution of respondents having complicated pregnancy by ANC pattern $(n=73)$

\begin{tabular}{|l|c|c|}
\hline ANC pattern & Frequency & Percentage \\
\hline Regular & 55 & 75.3 \\
\hline Irregular & 10 & 13.7 \\
\hline None & 5 & 6.8 \\
\hline Occasionally & 3 & 4.1 \\
\hline Total & 73 & 100 \\
\hline
\end{tabular}

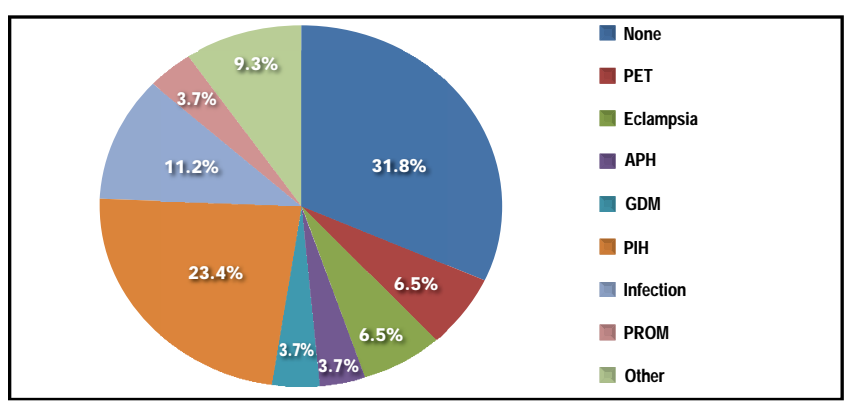

Figure-1: Distribution of the antenatal complications ( $n=107)$

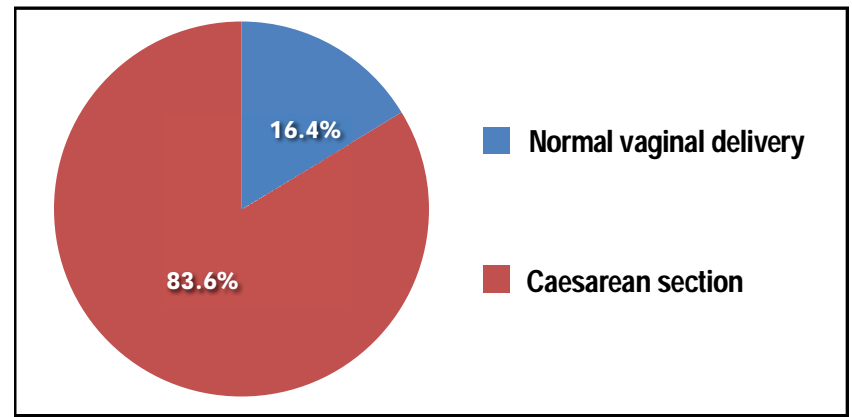

Figure-2: Distribution of mode of delivery of complicated pregnancy $(n=73)$

Table-II: Distribution of respondents having complicated pregnancy by type of complications during delivery $(n=73)$

\begin{tabular}{|l|c|c|}
\hline Complication during delivery & Frequency & Percentage \\
\hline No complication & 35 & 47.9 \\
\hline Malpresentation & 7 & 9.6 \\
\hline Prolonged labour & 5 & 6.8 \\
\hline Obstructed labour & 5 & 6.8 \\
\hline Eclampsia & 7 & 9.6 \\
\hline Other & 14 & 19.2 \\
\hline Total & $\mathbf{7 3}$ & 100 \\
\hline
\end{tabular}

Table-III: Distribution of respondents having complicated pregnancy by type of post-delivery complications $(n=73)$

\begin{tabular}{|l|c|c|}
\hline Complication after delivery & Frequency & Percentage \\
\hline No complication & 61 & 83.6 \\
\hline Excessive hemorrhage & 5 & 6.8 \\
\hline Convulsion & 4 & 5.5 \\
\hline Retained placenta & 3 & 4.1 \\
\hline Total & $\mathbf{7 3}$ & 100 \\
\hline
\end{tabular}

Table-IV: Association of Antenatal complication with Mode of delivery $(n=107)$

\begin{tabular}{|l|c|c|c|}
\hline \multirow{2}{*}{$\begin{array}{l}\text { Antenatal } \\
\text { complication }\end{array}$} & \multicolumn{2}{|c|}{ Mode of delivery } & \multirow{2}{*}{ Statistics } \\
\cline { 2 - 3 } & NVD & Caesarean & \\
\hline Yes & $12(16.4)$ & $61(83.6)$ & $\begin{array}{c}x^{2}=11.257 \\
d f=1 \\
p<0.001\end{array}$ \\
\hline No & $16(47.1)$ & $18(52.9)$ & \\
\hline
\end{tabular}

\section{Results}

Among the 107 respondents about $68.2 \%$ had antenatal complication and about $31.8 \%$ had no antenatal complication. Among women having pregnancy complications; $23.4 \%$ had history of pregnancy induced hypertension (PIH) about $11.2 \%$ had history of infections, about $3.7 \%$ had history of gestational diabetes mellitus (GDM). Distribution of the mode of delivery among the women with complicated pregnancy was about $83.6 \%$ delivered by caesarean section and only $16.4 \%$ delivered by normal vaginal delivery. Among the women with complicated pregnancy $61.6 \%$ caesarean section were due to pregnancy complications, about $16.4 \%$ due to history of previous 
caesarean section and about $4.1 \%$ mostly elective and the rest delivered by normal vaginal delivery. Among the women having complicated pregnancy $83.6 \%$ had no complication and $6.8 \%$ developed excessive hemorrhage after delivery. Among the women with complicated pregnancy about $47.9 \%$ had no complication during delivery, about 9.6 had mal-presentation, about $6.8 \%$ developed prolonged labour, about $6.8 \%$ had history of obstructed labour, and about $9.6 \%$ developed Eclampsia. About $69.9 \%$ had no previous history of pregnancy complications and only $30.10 \%$ had previous history of pregnancy complications. Among the women with complicated pregnancy $75.3 \%$ had regular antenatal check-up (ANC), about $13.7 \%$ had irregular ANC, about $6.8 \%$ had no history of ANC and about $4.1 \%$ had occasional history of ANC. There was significant association of Antenatal complication with Mode of delivery $(p<0.05)$.

\section{Dscussion}

In this study, among the respondents about $68.2 \%$ had antenatal complications and about $31.8 \%$ had no antenatal complication. As the study place was in a tertiary level hospital in Dhaka city so most of them were referred from other places. Among women having pregnancy complications $23.4 \%$ had history of $\mathrm{PIH}$, about $11.2 \%$ had history of Infections of the reproductive tract, about $6.5 \%$ had history of PET, about $6.5 \%$ developed eclampsia, APH developed in about $3.7 \%$ women, history of GDM were $3.7 \%$, about $3.7 \%$ of women had history of PROM and about 9.3\% had some other complications. An article published in 2010 reported that PIH, Preeclampsia or Toxemia affects about $5 \%$ to $10 \%$ of all pregnant women in Africa and America ${ }^{15}$. As that article was of a developed country that's why the rate is little bit less than this study.

In this study about $83.6 \%$ delivered by caesarean section and only $16.4 \%$ delivered by normal vaginal delivery. The cause of these huge percentage of caesarean sections were due to maximum number of the respondents having history of antenatal complications and many of them were referred from some other hospital after trial for normal vaginal delivery and some cesareans were done due to failed trial in the study place. Some study found that PROM was associated with high rate of caesarean section ${ }^{16-19}$. The mode of delivery of those study was also similar to this study.

Among the women with complicated pregnancy about $61.6 \%$ caesarean section were done due to pregnancy complications, about $16.4 \%$ due to history of previous caesarean section and about $4.1 \%$ mostly elective and the rest delivery by normal vaginal delivery. Among them about $83.6 \%$ had no complications after delivery, only $16.4 \%$ developed complications after delivery.

Among the women with complicated pregnancy about $47.9 \%$ had no complication during delivery, about $9.6 \%$ had malpresentation, about $6.8 \%$ developed prolonged labour, about $6.8 \%$ had history of obstructed labour, and about $9.6 \%$ developed postpartum eclampsia. An article published that about 5\%-6\% of pregnant women with preeclampsia may develop eclamsia ${ }^{20-21}$. As it was published in a developed country the rate is less than this study.
There was significant association of pregnancy complication with mode of delivery $p(<0.05)$. In case of women with pregnancy complication about $83.4 \%$ delivered by caesarean section and only $16.4 \%$ delivered by normal vaginal delivery. A study report showed that in case of pregnancy complication like GDM the rate of caesarean section was $61.1 \%$ and NVD only $29.6 \%$ of cases ${ }^{22}$. The rate of caesarean section of this study is nearly similar to that study.

In this study it was found that pregnancy complication is directly associated with low birth weight, caesarean section and preterm delivery, but may not be associated with birth asphyxia. From this study it was also found that preterm delivery is directly associated with low birth weight and birth asphyxia, birth asphyxia is associated with low birth weight of newborn. These findings are similar to the findings of several studies ${ }^{23,24}$.

\section{Conclusion}

Women die throughout the world due to wide range of complications during pregnancy and child birth. Though every pregnancy is at risk but early detection of high risk cases could be managed properly. Most of these complications and adverse outcome related to pregnancy could be minimized the adverse outcome by prompt and proper intervention. Mode of delivery has direct influence on maternal life and wellbeing and also newborn. In this regard Emergency Obstetric Care is of great importance to save mother and child.

\section{Limitation of the study}

1. Due to limited time, the sample size was small. Only 107 recently delivered mothers of the study place were researcher's study population. So the findings of this study may not have exactly similar result as might be obtained from a large scale survey.

2. Most of the respondents were from urban area. So the findings will not be the actual picture of entire country especially of rural area of Bangladesh.

3. The study place was tertiary level hospital in Dhaka city. So the results of the study may be different from studies in those hospital with poor health care facility and scarcity of skilled health care professionals

\section{References}

1. UNPF. Maternal health. Accessed on 2017-01-29.

2. GBD 2013 Mortality Causes of Death Collaborators. Global, regional and national age-sex specific all-cause and cause-specific mortality for 240 causes of death, 1990-2013: A systematic analysis for the Global Burden of Disease Study 2013. Lance. 2015; 385(9963):117-71.

3. WHO. Maternal mortality: Fact sheet $N^{\circ} 348$ ". Accessed on 20 June 2014.

4. Molina RL, Pace LE. A Renewed Focus on Maternal Health in the United States. The New England Journal of Medicine. 2017; 377(18):1705-7.

5. WHO, UNICEF, UNFPA, World Bank Group and the United Nations Population Division. Trends in Maternal Mortality: 2000 to 
2017. Geneva, World Health Organization, 2019:1-104.

6. Islam R, Adams AM, Hasan SM et al. Making information and communications technologies (ICTs) work for health: Protocol for a mixed-methods study exploring processes for institutionalizing referenced health information systems to strengthen maternal neonatal and child health (MNCH) service planning, referral and oversight in urban Bangladesh. BMJ Open. 2020; 10:e032820.

7. Kilpatrick SK, Ecker JL. Severe maternal morbidity: Screening and review. American Journal of Obstetrics and Gynecology. 2016; 215(3):17-22.

8. Khlat $\mathrm{M}$, Ronsmans $\mathrm{C}$. Deaths attributable to childbearing in Matlab, Bangladesh: indirect causes of maternal mortality questioned. American Journal of Epidemiology. 2000; 151(3):300-6.

9. Conde-Agudelo A, Belizán JM, Lammers C. Maternal-perinatal morbidity and mortality associated with adolescent pregnancy in Latin America: Cross-sectional study. American Journal of Obstetrics and Gynecology. 2005; 192(2):342-9.

10. WHO. Maternal mortality. Accessed on 03 August 2021.

11. WHO, UNICEF, UNFPA and the World Bank. Trends in maternal mortality: 1990 to 2010. WHO, UNICEF 2012:1-44.

12. World Health Organization. WHO Applying the lessons of maternal mortality reduction to global emergency health". Accessed on 2019-08-02.

13. Sereen T, Deborah M. Maternal mortality in context. Social Science \& Medicine. 1994; 38(8):1091-110.

14. Kuhnt J, Vollmer S. Antenatal care services and its implications for vital and health outcomes of children: evidence from 193 surveys in 69 low-income and middle-income countries. BMJ Open. 2017; 7(11):e017122.
15. Chanda SK, Ahammed B, Howlader MH et al. Factors associating different antenatal care contacts of women: A cross-sectional analysis of Bangladesh demographic and health survey 2014 data. Plos One. 2020; 15(4):e0232257.

16. Shah B, Krishnan N, Kodish SR et al. Applying the Three Delays Model to understand emergency care seeking and delivery in rural Bangladesh: A qualitative study. BMJ Open. 2020; 10:e042690.

17. Baresh-Josiah D, Mynttic, Augstin A et al. The "three delays" as a framework for examining maternal mortality in Haiti. Social Science \& Medicine. 1998; 46(8):981-93.

18. Khan KS, Wojdyla D, Say $L$ et al. WHO analysis of causes of maternal death: A systematic review. Lancet. 2006; 367(9516): 1066-74.

19. United Nations. Goal 3: Ensure healthy lives and promote well-being for all at all ages. Accessed on 03 August 2021.

20. Gestational Hypertension (Pregnancy inducced Hyper tension), Source: http://healthpages.org/pregnancy/pregnancyinduced- hypertension-pih/, June 252010.

21. Kilpatrick SK, Ecker JL. Severe maternal morbidity: Screening and review. American Journal of Obstetrics and Gynecology. 2016; 215(3):17-22.

22. Alaf SK. Diabetes during Labour: Types, mode of Delivery and Fetal Outcome in "Erbil Maternity Teaching Hospital. Journal of Zonkoy Sulaimani. 2008; 11(1):117-125.

23. Furukawa $\mathrm{S}$, Sameshima $\mathrm{H}$, Tsuyomu I et al. Is the Perinatal Outcome of Placental Abruption Modified by Clinical Presentation? Journal of Pregnancy. 2011; 2011:1-5

24. Alaf SK, Omer DI. Prevalence and clinical observations of Gestational Trophoblastic Diseases in Maternity Teaching Hospital in Erbil City. Wseas Transactions on Biology and Biomedicine. 2010; 7(3):190-9. 